\title{
Design of woven fabrics using DYF1.0 specialized software code
}

\author{
Radostina A. Angelova ${ }^{1}$, Lyuben Krumov ${ }^{1}$ \\ ${ }^{\prime}$ (Department of Textiles, Technical University of Sofia, Bulgaria)
}

\begin{abstract}
DYF1.0 software code for design of woven fabrics is presented. The need for fast calculation of the parameters of a new fabric is discussed. The module for designing of fabrics and its six menus are presented in details. The parameters needed for setting the winding, warping, sizing and weaving of the new fabric, are presented in terms of their calculation using the DYF1.0 software code.
\end{abstract}

Keywords: DYF1.0 software code, design of fabrics, fabrics' properties, specialized software

\section{Introduction}

The design of the woven fabrics is associated with the following possible cases of production:

- Creation of a new tissue;

- Reproduction of an already woven sample, which has been analyzed;

- Improving the quality of an already put into production fabric.

Each of these cases requires the calculation or selection of the most appropriate parameters of the woven structure according to its application, appearance, and desired operational characteristics.The design of the woven fabric ends with a set of results expressed in a written form, which constitute the project of the fabric. According to this project, the necessary raw materials are prepared, the technological operations are determined, the necessary machines parameters are set, the operating modes are specified, a specimen is manufactured, and laboratory testing of the gray and finished fabric is performed. If necessary, adjustments and fine-tuning of all parameters are made so as the project to be finalized before proceeding to the production of samples in larger quantities and the final mass production.

The sequence of the woven fabric design includes a number of steps, and the definition of the technical requirements among them is especially important. The technical requirements are based on specific formulas that have to be applied in a specific sequence in the presence of specific inputs.

The technical requirements are related to:

a/ Characteristics of the threads. The number of the sets of warp and weft threads are determined as components of the fabric structure, together with the composition and structural characteristics of the yarns, their linear densities and limitations on the number, the weight of the warp and the weft threads in the fabric, the requirements for the physical and mechanical properties of the threads, and their resistance to laundry, dry cleaning, temperature effects, moisture, microorganisms, oils, etc.

b / Characteristics of the fabric: The linear dimensions of the fabric are determined together with the composition of whole fabric, the desired structural effect of the weave, the type of the finishing treatments and additional coatings, the mass of one linear meter and one square meter of both the gray and the finished fabric, the physical and mechanical requirements for the fabric strength in warp and weft directions, the stretching, the wrinkling and abrasion resistance, pilling resistance, the desired visual appearance of the surface, the phase of construction, the ratio of the warp and weft densities, etc.

c/ Aesthetic requirements for fabric color, figured elements in the pattern, shadows, type of the face surface, touch, etc.

\section{d/ Economic requirements.}

The use of a software program to perform the design of a woven fabric gives an exceptional comfort for engineers and designers, as it allows quick changing of the calculations when changing an element of the fabric technical project. There are many CAD systems that facilitate the design of the fabrics and the elaboration of the production of documentation. The CAD systems are very often a part of a specific type of a weaving machine and can design fabrics from the basic weaves to complex jacquard weaves [1-4]. Along with this several research papers are dealing with visualization and simulation of woven fabrics [5-7]. Software packages that visualize the structure and predict the properties of the fabrics are also developed $[8,9]$.

This paper presents the DYF1.0 software code, designed to consistently calculate the stages of the technical project of woven fabric design. The code is developed in the frame of the Microsoft DotNet Frameworks 4.0, which enables easy installation and use on PCs that runs Microsoft Windows. 


\section{Design of Fabrics Using DYF1.0 Specialized Software}

The flow chart of the processes of woven fabric's manufacturing is shown in Fig. 1. The scheme reflects the design of a new fabric, based on a similarity between it and a reference woven fabric, which has been already produced. This explains the first stage in the technological flow chart - selection and analysis of an existing fabric. The actual design of the new woven tissue is associated with the second stage in Fig. 2 development of a technical project. The DYF1.0 software code is oriented towards the accomplishment of this stage of the production flow. The other processes - winding, warping, sizing, tying-in and weaving - are related to the physical manufacturing of the fabric.

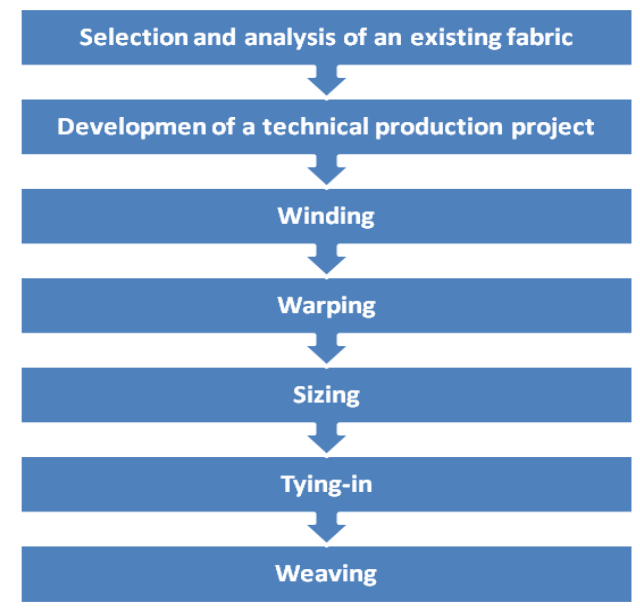

Fig. 1 Flow chart of the processes for woven fabric's manufacturing

DYF1.0 software code was developed in two modules - design of fabrics and design of yarns. The programming language $\mathrm{C \#}$ was used and Fig. 2 shows part of the code for the module for fabrics' design.

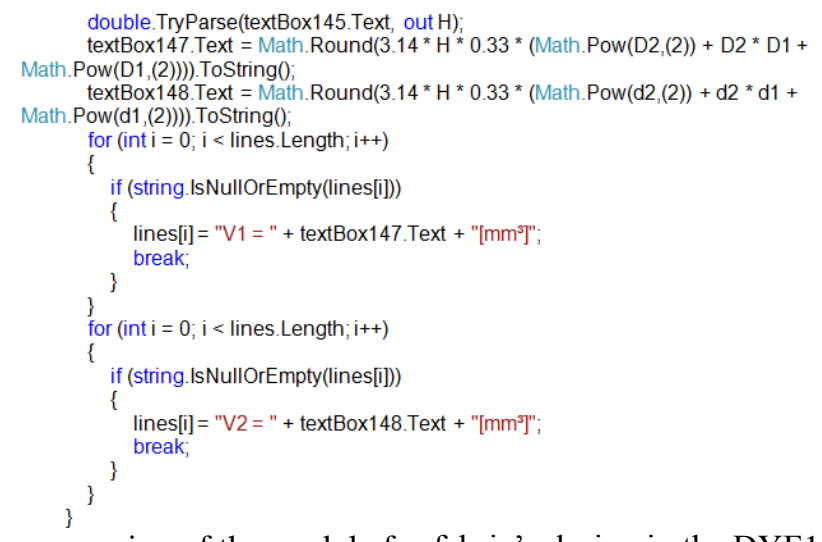

Fig. 2 Part of the programming of the module for fabric's design in the DYF1.0 software code

To initiate the predictions with the DYF1.0 software code some technical data of the gray fabric has to be set as input values for the calculations, for example:

- Width of the gray tissue;

- Fabric width in the reed;

- Linear density of both warp and weft threads;

- Warp and weft densities of the gray cloth;

- Number of warp threads;

- Number of threads in the selvages;

- Number of the reed.

The DYF1.0 software code offers 6 menus in the module for designing woven fabrics. In the first menu the data of the similar, existing fabric that has been selected to serve as a basis for design, have to be filled-in. The boxes in white require data entry, and the boxes, colored in green, display the calculated values. In addition, the index of each variable is written on the left of each box, and its dimension is placed on the right side of the box. By pressing the "Yes" button, the program calculates the corresponding variable and displays the result in the green box. The program is currently developed in Bulgarian. 
In the menu "Development of the technical project for weaving", shown in Fig. 3, the following parameters are consistently calculated:
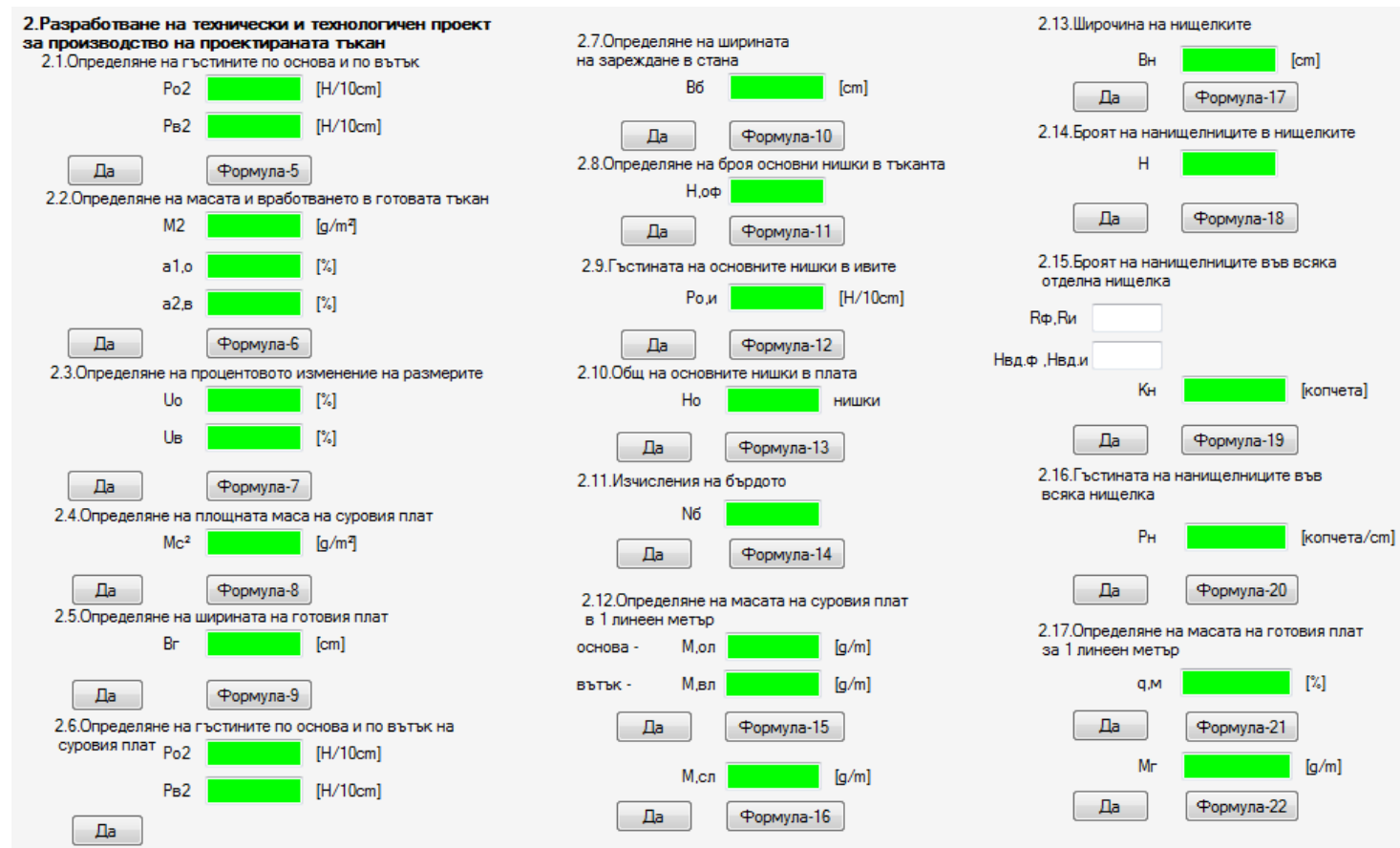

Fig. 3 Menu "Development of the technical project for weaving"

- $\quad$ Mass per 1 meter of gray cloth, g/m; the mass of the warp and the weft threads in 1 meter is used.

- Weft waviness; it is based on the width of the cloth in the reed and the width of the gray fabric, $\mathrm{mm}$.

- Mass of $1 \mathrm{~m}^{2}$ of the finished fabric, $\mathrm{g} / \mathrm{m}^{2}$; it requires information about the width of the finished fabric.

- Width shrinkage of the finished fabric.

- Warp and weft density f the finished fabric.

- Weight and the waviness of the finished fabric.

- Percentage of cloth's dimensional changes during finishing.

- Mass per unit area of the gray cloth.

- Loom width setting, based on the width of the raw fabric and the weft thread waviness.

- Number of warp threads in the fabric.

- Warp threads density in the selvages.

- Total number of warp threads in the fabric.

- Number of the reed.

- Mass of warp and weft in 1 meter of gray cloth.

- Mass of the gray cloth in 1 meter.

- Width of the shafts.

- Percentage of the fabric's mass change at finishing.

- Mass of 1 meter of the finished fabric.

The third menu calculates the parameters of the winding process - Fig. 4. The following are consistently determined:

- Speed of the thread during winding.

- Length of the slot of the defect cleaning device.

- Yarn tension at rewinding.

- $\quad$ Length of the thread in the bobbin.

- Mass of the bobbin.

- Timing for winding the bobbin.

- Theoretical efficiency.

- Actual efficiency. 

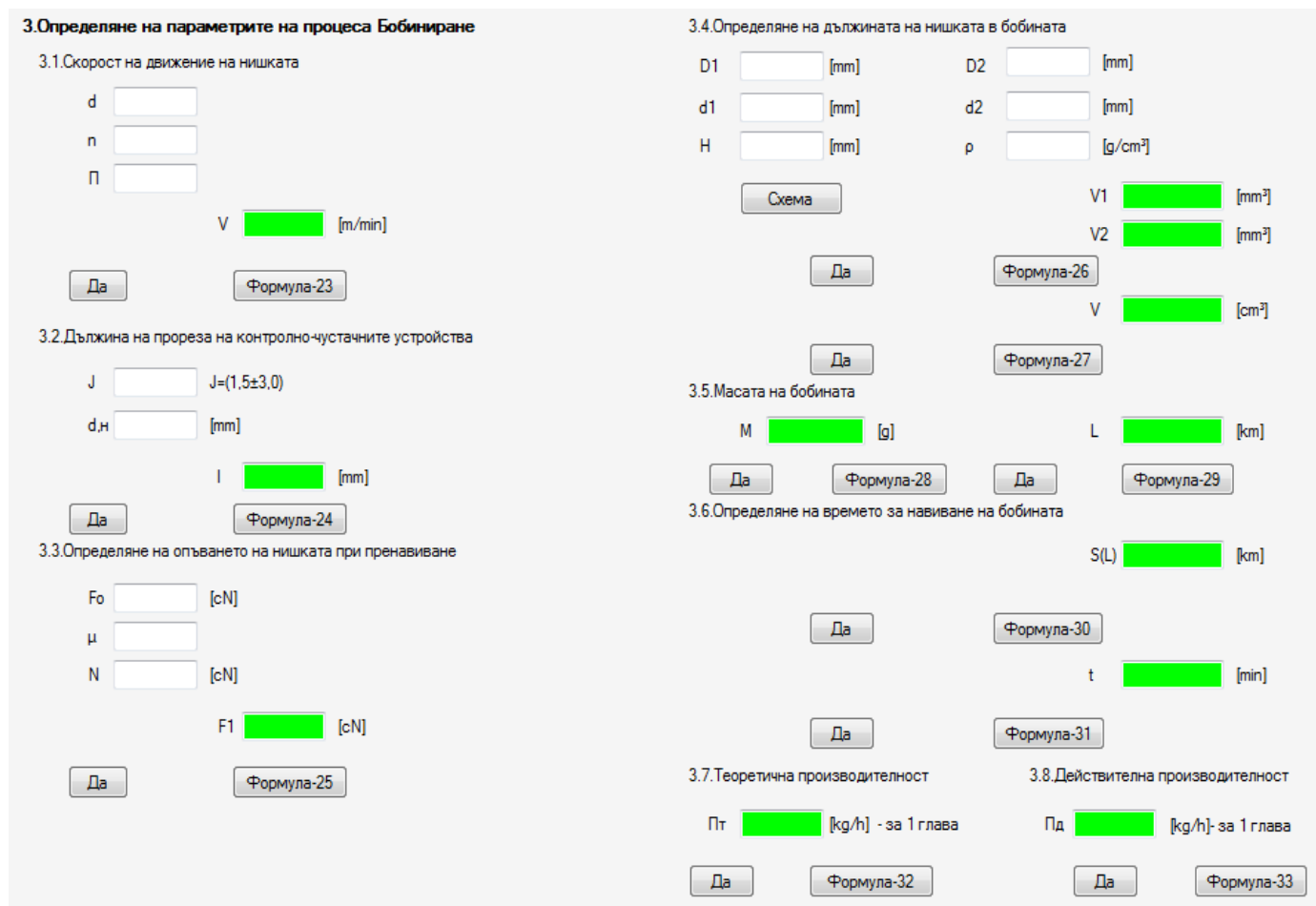

Fig. 4 Menu "Winding process"

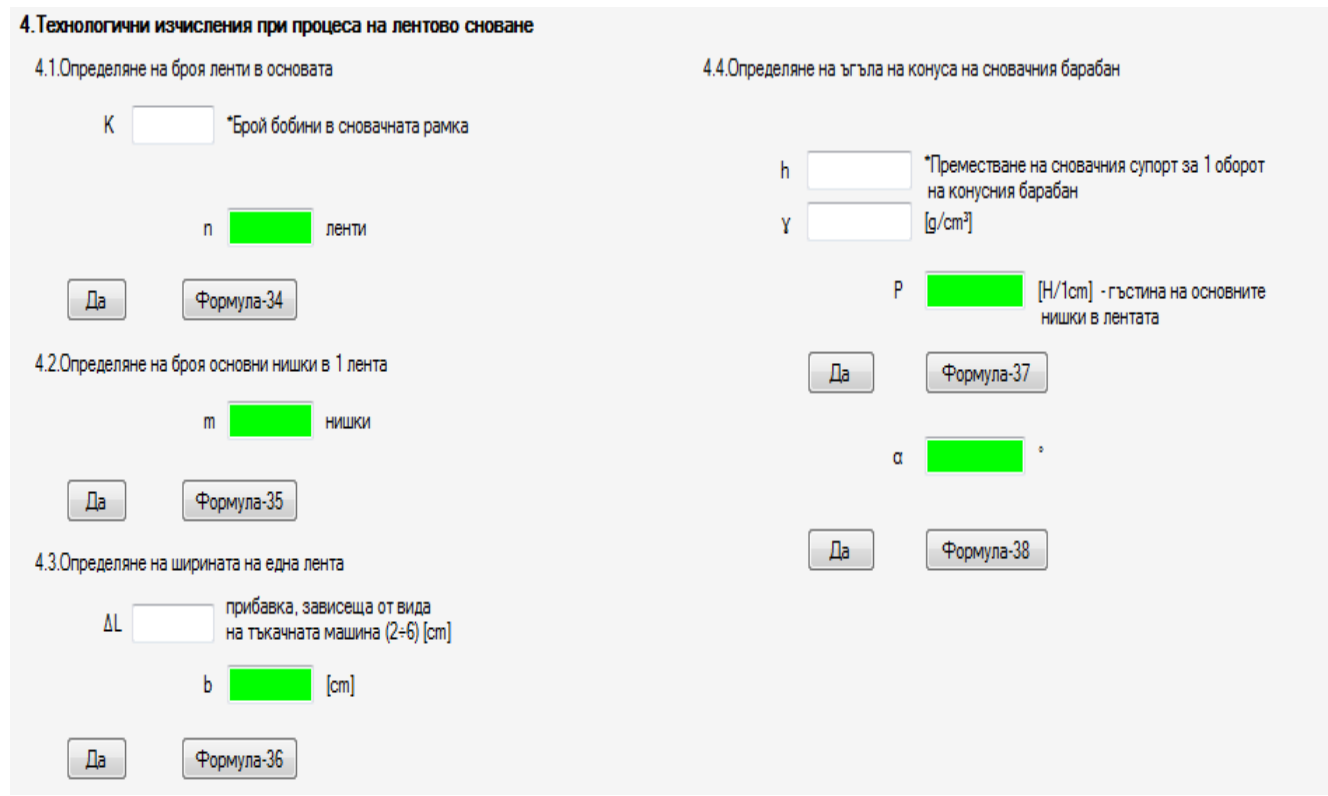

Fig. 5 Menu "Warping process"

The fourth menu helps the design of the parameters of the warping process - Fig. 5:

- Number of the sections on the beam.

- Number of warp threads in a section.

- Width of a section.

- Threads density in a section.

- Angle of the beam.

The parameters of sizing are calculated by using the fifth menu, shown in Fig. 6. It includes the calculation of:

- Correction coefficient reflecting the ratio between the thickness of the threads of the designed woven fabric and the reference fabric.

- Correction coefficient reflecting the ratio between the number of warp threads in 1 tooth of the reed and the reference fabric. 


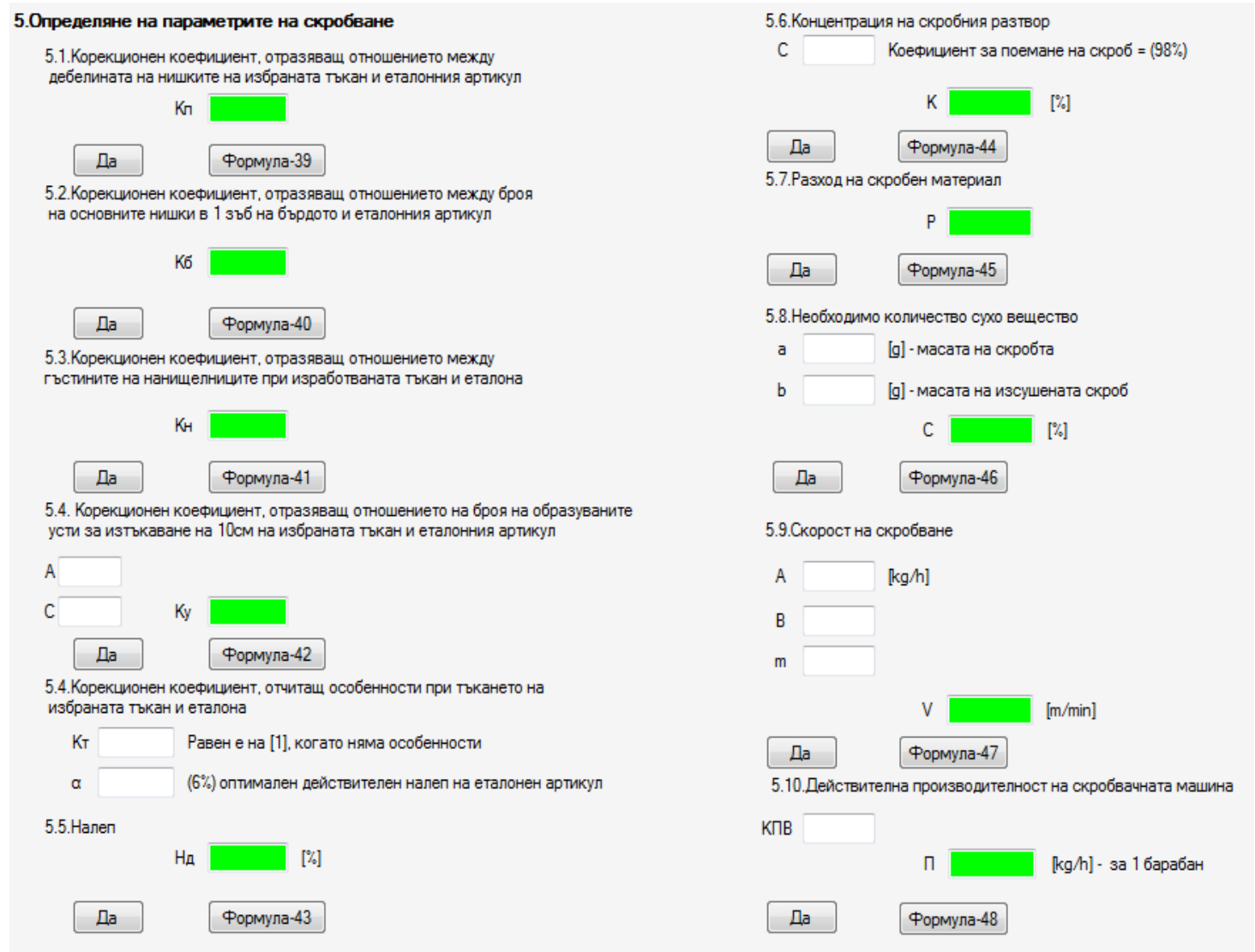

Fig. 6 Menu "Sizing process"

- Correction coefficient reflecting the relationship between the density of the heddles for the designed fabric and the reference one.

- Correction coefficient reflecting the ratio of the number of sheds opened for the weaving of $10 \mathrm{~cm}$ of cloth for designed fabric and the reference one.

- Correction coefficient considering the peculiarities in the weaving of the designed fabric and the reference one.

- Concentration of the sizing solution.

- Consumption of the sizing solution.

- Required quantity of the dry component.

- Speed of the sizing.

- Actual efficiency of the sizing machine

The last menu in this module helps the prediction of the parameters of the tying-in process, namely:

- Calculation of the reed number.

- Number of the heddles in the shafts.

- Total number of the heddles.

- Density of the heddles in a shaft.

- Theoretical efficiency.

- Actual efficiency.

Figure 7 shows a print screen of the menu.

The software code is also very suitable for training and education as it introduces opportunities for familiarization with the basic formulas for calculation - the window with the formula appears on the same screen, and clicking on the basic screen remains open, but inactive so as to be called and consulted quickly.

\section{Conclusions}

DYF1.0 software code provides a useful combination of tools for designing of yarns and fabrics. It is one of the CAD software packages, able to calculate and predict the woven fabrics parameters, needed for the successful production in the weaving mill. The software package can be used also for the education of engineers and student in textile engineering and design. The software is open and will be further developed, adding more methods for designing the parameters of yarns and fabrics. 

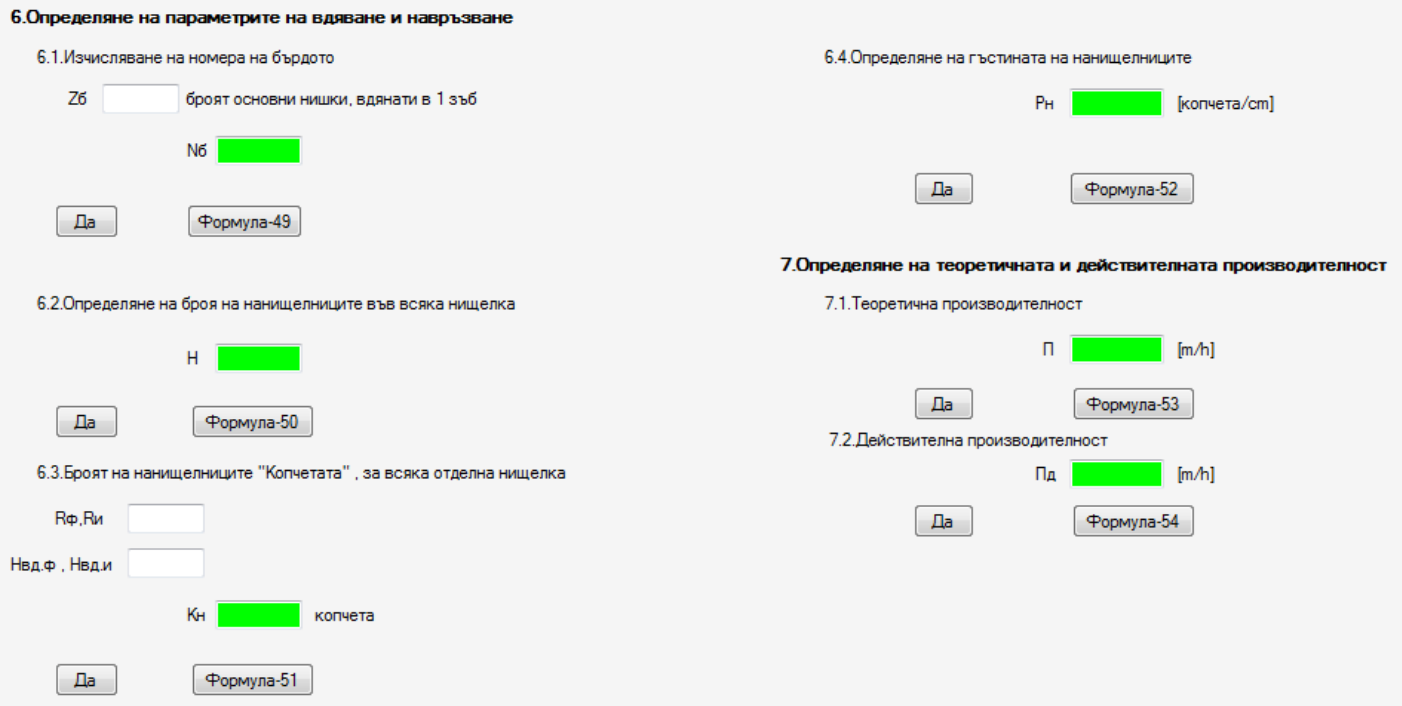

7.1. Теоретична производителност

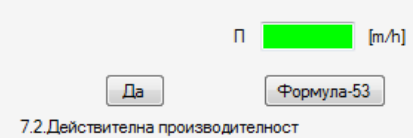

72 Действителна производителност

Пд $\square[\mathrm{m} / \mathrm{h}]$

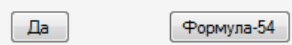

Fig. 7 Menu "Tying-in process"

\section{References}

[1] EAT CAD/CAM weaving system, www.designscopecompany.com

[2] DesignScope victor CAD/CAM weaving system, www.designscopecompany.com.

[3] NedGraphics CAD/CAM weaving system, www.nedgraphics.com.

[4] ScotCad Textiles Limited CAD/CAM weaving system, www.scotweave.com.

[5] Zhang, J., Baciu, G., Zheng, D., Liang, C., Li, G., \& Hu, J. (2013). IDSS: A novel representation for woven fabrics. IEEE transactions on visualization and computer graphics, 19(3), 420-432.

[6] Özdemir, H., \& Başer, G. (2008). Computer simulation of woven fabric appearances based on digital video camera recordings of moving yarns. Textile Research Journal, 78(2), 148-157.

[7] Lin, H., Zeng, X., Sherburn, M., Long, A. C., \& Clifford, M. J. (2012). Automated geometric modelling of textile structures. Textile Research Journal, 82(16), 1689-1702.

[8] Verpoest, I., \& Lomov, S. V. (2005). Virtual textile composites software WiseTex: Integration with micro-mechanical, permeability and structural analysis. Composites Science and Technology, 65(15), 2563-2574.

[9] Kolčavová Sirková, B., \& Mertová, I. (2013). Prediction of woven fabric properties using software ProTkaTex. Autex Research Journal, 13(1), 11-16. 